Why do ideas get more creative across time? An executive interpretation of the serial order effect in divergent thinking tasks.

By: Roger E. Beaty \& Paul J. Silvia

Roger E. Beaty \& Paul J. Silvia (2012). Why do ideas get more creative across time? An executive interpretation of the serial order effect in divergent thinking tasks. Psychology of Aesthetics, Creativity, and the Arts, 6(4), 309-319.

Made available courtesy of the American Psychological Association: http://psycnet.apa.org/journals/aca/6/4/309/

This article may not exactly replicate the final version published in the APA journal. It is not the copy of record. Figures and/or pictures may be missing from this format of the document.

\begin{abstract}
:
The serial order effect- the tendency for later responses to a divergent thinking task to be better than earlier ones-is one of the oldest and most robust findings in modern creativity work. But why do ideas get better? Using new methods that afford a fine-grained look at temporal trajectories, we contrasted two explanations: the classic spreading activation account and a new account based on executive and strategic aspects of creative thought. After completing measures of fluid intelligence and personality, a sample of young adults $(n=133)$ completed a 10-min unusual uses task. Each response was time-stamped and then rated for creativity by three raters. Multilevel structural equation models estimated the trajectories of creativity and fluency across time and tested if intelligence moderated the effects of time. As in past work, creativity increased sharply with time and flattened slightly by the task's end, and fluency was highest in the task's first minute and then dropped sharply. Intelligence, however, moderated the serial order effectas intelligence increased, the serial order effect diminished. Taken together, the findings are more consistent with a view that emphasizes executive processes, particularly processes involved in the strategic retrieval and manipulation of knowledge, than the simple spreading of activation to increasingly remote concepts.
\end{abstract}

Keywords: creativity | divergent thinking | executive processes | intelligence | multilevel modeling | serial order effect | psychology

\title{
Article:
}

Creativity research has many ideas, both old and new, about how people come up with new ideas. In the present research, we propose some new ideas about one of creativity research's oldest ideas: the serial order effect in idea generation ( Christensen, Guilford, \& Wilson, 1957). 
One of the many landmark discoveries by Guilford and his group was that ideas tend to get increasingly original, novel, and remote as time passes. In a divergent thinking task, for example, it's more likely for the good ideas to appear later and the more mundane ideas to appear earlier. Guilford's idea had a huge influence on associative theories of creative thought, particularly theories founded on spreading activation in semantic memory ( Mednick, 1962; Wallach \& Kogan, 1965).

During the half-century since Guilford's work, many experiments have replicated the serial order effect: as time passes, creativity goes up and fluency — the number of responses-goes down ( Parnes, 1961; Ward, 1969). And there's apparently no debate about why this happens: all research explains the serial order effect with reference to low-level associative processes typical of semantic networks. In contrast, we propose a new explanation for the serial order effect. We contend that the growth of creativity across time represents the influence of top-down executive influences on creative thought, such as strategy use, interference management, and directed search and retrieval processes. The serial order effect—long viewed as a foundation for associative models of creativity - might instead be yet more evidence for an executive interpretation of divergent thinking and creative thought ( Nusbaum \& Silvia, 2011a; Silvia \& Beaty, 2012).

The present research thus provides a new look at the serial order effect. After reviewing past work, we discuss some methodological limitations and show how modern methods and statistical models can overcome them. We then present an experiment that examined the influence of fluid intelligence-an ability central to executive cognitive processes ( Carroll, 1993; Conway, Kane, \& Engle, 2003) —on the creativity and fluency of divergent thinking across time. Taken together, the results both illustrate new methods for studying the serial order effect and suggest reconsidering why it happens.

\section{The Serial Order Effect}

Many studies, using a variety of methods and samples, have found that later ideas tend to be better than early ideas. Christensen et al. (1957), in the first demonstration, gave adult participants a series of divergent thinking tasks (e.g., unusual uses, plot titles, impossible situations) and instructed them to come up with ideas that were either appropriate or clever (i.e., “interesting-arousing, catchy, inviting, or novel," p. 84). Their research was inspired by the emerging literature on verbal fluency tasks, which had found that low-frequency words tend to appear later ( Bousfield \& Barclay, 1950; Bousfield \& Sedgewick, 1944). Each divergent thinking task was timed between 12 and 16 minutes, and participants were asked to draw lines under their last response at 2-min intervals to mark the time period. Across several studies, Christensen et al. found that creativity increased as time passed. This was apparent in descriptive curves of temporal trends and in statistical tests that compared responses during the first half of the task versus the second half. 
Later work replicated and extended the serial order effect. Several studies showed the effect with children ( Milgram \& Rabkin, 1980; Phillips \& Torrance, 1977; Runco, 1986; Ward, 1969); evaluated the effect for different kinds of tasks ( Johns, Morse, \& Morse, 2001; Phillips \& Torrance, 1977); and explored a range of scoring methods, such as subjective ratings ( Parnes, 1961), flexibility ( Runco, 1986), and originality and uniqueness ( Runco, 1986; Ward, 1969). The typical methodological approach has been to offer more time than the usual divergent thinking task (or to have no time limit) and then to test for the serial order effect by splitting the scores into two groups and comparing them.

With the benefit of hindsight and statistical advances, we can identify some methodological challenges that were difficult for past research to handle. The first limitation is the kind of within-person statistical tests that were available to past researchers. Nearly all studies did a within-person median split and then compared the halves. In some cases, the scores were split based on the task's median (e.g., after 5 minutes during a 10 minute task); in other cases, the scores were split at each person's own median (e.g., after the fourth response for a person who gave eight responses). Readers familiar with multilevel modeling will recognize this difference as analogous to centering within-person data at the overall sample's mean versus each person's own mean ( Enders \& Tofighi, 2007). The perils of median splits have become more understood since most of the serial order research was conducted (e.g., Cohen, 1983; Maxwell \& Delaney, 1993). Among other problems, a median split puts distant responses into the same category and close responses into different categories. For a participant with 20 responses, for example, the two halves would consist of responses 1-10 and responses 11-20. Response 11 is much closer to 10 than 10 is to 1 , but 10 and 11 end up in different categories.

A second and more subtle limitation is the data sparseness that results from variation in fluency. Because few people generate a lot of responses, and because responses taper off as time passes, few people have responses late in a task. In the serial-order curves depicted by Christensen et al. (1957, p. 84), for example, participants with fewer than 6, 8, or 10 responses (depending on the task) were excluded. The resulting curves thus fail to represent the true temporal trends in the sample, and the findings are probably biased by the extensive listwise deletion ( Enders, 2010). In Ward's (1969) research, most participants had no responses at the later time points, so some people were dropped from many analyses. That decision probably biased the findings in complex ways, given that Ward found that the more creative people in his sample were less likely to be dropped.

In short, past work lacked the statistical tools needed to harness the extensive within-person data that divergent thinking tasks provide. This is an instance of the broader struggle that psychological research had within repeated-measures data prior to the development of advanced statistical models for nested data structures ( Singer \& Willett, 2003). Modern methods for repeated-measures data, particularly multilevel models ( Luke, 2004; Raudenbush \& Bryk, 2002), can overcome both limitations. First, unlike repeated-measures ANOVA, multilevel models allow each person to have a different number of within-person scores. It is thus easy to 
handle the fact that people generate different numbers of responses. Second, multilevel models allow time-varying predictor scores, which means simply that people can vary in their time-ofoccurrence scores. In an ANOVA framework, the time-of-occurrence scores would have to be equated across people by classifying the responses into time bins, such as into above-median and below-median bins (e.g., Milgram \& Rabkin, 1980; Parnes, 1961) or into successive 2-min or 10-s bins (e.g., Christensen et al., 1957; Ward, 1969). In a multilevel model, in contrast, researchers can simply measure when responses were given and then use those time values to predict the responses' creativity. Researchers thus needn't drop participants with too few or too many responses.

\section{Explaining the Serial Order Effect}

The serial order effect is unusually robust, so the important question is why ideas get more creative across time. The most common explanation comes from the classic associative model of creativity pioneered by Mednick (1962). According to this view, divergent thinking is a process of spreading activation in semantic memory, and creative ideas come from activating and connecting distant concepts. This model implies a spatial metaphor of creative ideation: people must first pass highly related, accessible responses (e.g., table-chair) before they arrive at remote and unusual ones ( Moran, 2009). The Remote Associates Test (RAT; Mednick, 1962), a task designed to assess this conception of creative ability, remains a popular measure 50 years later ( Sawyer, 2011).

Mednick's associative mechanism provides a simple and appealing explanation for temporal trends in divergent thinking. It takes time for increasingly remote associations to become active and available, so the serial order effect reflects the gradual spreading of activation from close and obvious associations to remote and unusual ones. With enough time, activation will spread to distal associates on the fringe of the network, and those are likely to be original and novel ( Milgram \& Rabkin, 1980; Wallach \& Kogan, 1965; Ward, 1969). More generally, the spreading of activation through semantic networks remains an influential explanation for how divergent thinking happens and why some people are better at it than others ( Kaufman, 2009; Runco, 2007). Furthermore, an associative explanation reinforces the long-standing distinction between divergent thinking, which is broad, diffuse, and bottom-up, and convergent thinking, which is narrow, focused, and top-down.

Modern creativity research, however, has suggested that the classic divergent-versus-convergent distinction obscures many top-down, executive, and controlled aspects of creative thought. Recent research, for example, has highlighted the contributions of exercising top-down control over attention and cognition ( Benedek, Bergner, Könen, Fink, \& Neubauer, 2011; De Dreu, Nijstad, Bass, Wolsink, \& Roskes, 2012; Fink et al., 2009; Nusbaum \& Silvia, 2011a; Vartanian, 2009; Zabelina \& Robinson, 2010; Zabelina, Robinson, Council, \& Bresin, 2012), judging and refining initial ideas ( Finke, Ward, \& Smith, 1992; Gabora, 2005; Vartanian, 2011), and choosing and applying idea-generation strategies that vary in effectiveness ( Gilhooly, Fioratou, 
Anthony, \& Wynn, 2007). The trend toward viewing divergent thinking in terms of executive processes suggests that researchers should take a new look at the serial order effect. Executive processes unfold over time, too, and we think that the temporal operation of executive processes provides a plausible interpretation of why responses get more creative across time. Three executive processes in particular seem to change in ways that would correspond with increases in creativity.

First, people identify, use, and discard strategies during a divergent thinking task, and patterns of strategy use map on to patterns of creativity. Gilhooly et al. (2007), in a revealing set of studies, analyzed how people selected and changed cognitive strategies over the course of an unusual uses task. In the first of two experiments, participants were asked to "think aloud" as they worked through the task. Protocol analysis of the verbal reports ( Ericsson \& Simon, 1980) revealed several classes of strategies that people used to come up with unusual uses. The least creative responses resulted from a retrieval-based strategy — simply recalling preexisting uses from memory - whereas creative ideas were associated with other abstract strategies (e.g., disassembling the object and using the parts). Regarding serial order, Gilhooly et al. found a temporal structure to strategy use. Around $97 \%$ of the participants started with the memoryretrieval strategy, which generates mundane and obvious uses. Many participants never switched away from this strategy, but most eventually discarded it and switched to a more fertile strategy. As a result, strategy use over time would also create a serial order effect: responses become more creative as people discard poor ideation strategies in favor of better ones.

Second, executive switching - when people stop generating ideas from one conceptual category and switch to another-unfolds over time. Research on verbal fluency tasks, which are close cousins of divergent thinking tasks ( Carroll, 1993), shows that people higher in intelligence and working memory span switch categories more often ( Troyer, Moscovitch, \& Winocur, 1997; Unsworth, Spillers, \& Brewer, 2011). In both verbal fluency tasks and unusual uses tasks, people typically start with a salient and obvious category. For a brick task, people might start with "construction uses" by listing uses such as build a wall, fireplace, or garden path. Once a category is exhausted and people hit an impasse, they need to stop the search processes within a category, generate a cue for a new category, and then construct responses within it. Some people-people lower in intelligence and working memory span—have a harder time with such deliberate control of attention and cognition, so they switch less often and hence have fewer ideas in verbal fluency tasks ( Unsworth et al., 2011) and less creative ideas in unusual uses tasks ( Nusbaum \& Silvia, 2011a, Study 1). As with strategy use, switching has a temporal structure that would create a serial order effect: if people first exhaust an obvious category and then stop and switch to new idea categories, their later responses will be better than their earlier responses.

Third, interference management during a divergent thinking would lead to later responses being better than earlier ones. Creating good responses involves managing interference from obvious uses, previously generated responses, and responses closely connected to the object's salient features (e.g., a brick's color, shape, and density). Managing interference is a central executive 
process (Unsworth, 2010), and several cognitive abilities, particularly fluid intelligence and working memory span ( Burgess, Gray, Conway, \& Braver, 2011), predict how well people can do it. The fan effect, for example, refers to a type of interference that stems from an overactivation of shared conceptual information in long-term semantic memory ( Anderson, 1983b). People with low working memory spans experience more interference than high-spans during tasks where the number of shared concepts (or fans) increases ( Bunting, Conway, \& Heitz, 2004; Cantor \& Engle, 1993). Taken in the context of divergent thinking tasks, it's likely that the initial search for alternative uses activates highly related associates in semantic memory. Overcoming this source of interference and navigating beyond tightly knit conceptual knowledge requires executive processes and abilities associated with the control of attention. Like strategy use and switching, interference management has a temporal structure that would create a serial order effect: obvious, common ideas and object features come to mind first, so better responses come later when people overcome interference from obvious ideas and early responses.

The Present Study

The serial order effect is easy to replicate but hard to explain. The dominant explanation for the serial order effect is associative: responses get better as increasingly remote semantic concepts are activated. But executive processes unfold across time, too, and we have discussed how several of them unfold in ways that would generate a serial order effect. We think an executive explanation is at least as likely as an associative one, and the present experiment sought to gain evidence in support of our reinterpretation.

A straightforward way to examine the role of executive processes is to examine the role of fluid intelligence, a domain-general executive ability ( Carroll, 1993). People higher in fluid intelligence can use complex strategies more effectively ( Nusbaum \& Silvia, 2011a, Study 2), switch idea categories more often ( Nusbaum \& Silvia, 2011a, Study 1), manage interference (Unsworth, 2010), and discern patterns, rules, and structure in complex problems ( McGrew, 2005). Fluid intelligence is closely tied to working memory span ( Süß, Oberauer, Wittman, Wilhelm, \& Schulze, 2002), another ability fundamental to the deliberate control of cognition and attention. Fluid intelligence can thus represent variability in how well people can exert control over the mental resources needed to generate good ideas.

In our study, we measured the creativity of responses across an extended divergent thinking task. People had 10 minutes to generate unusual and creative uses for a brick. The software that controlled the task precisely recorded when each response was given, and multilevel models were used to estimate the trajectory of creativity across time. To examine the role of intelligence, we administered six standard tests of fluid intelligence, with an emphasis on nonverbal and visuospatial tasks. If the serial order effect reflects the unfolding of low-level spreading activation in semantic memory, then we wouldn't expect fluid intelligence to moderate it. But if the serial order effect reflects the unfolding of executive processes, then we would expect to find two things. First, people high in fluid intelligence should generate better, more creative responses 
overall, consistent with our claim that intelligence promotes creative thought ( Nusbaum \& Silvia, 2011a; Silvia \& Beaty, 2012). Second, fluid intelligence should moderate the serial order effect. Specifically, time should matter more for people low in intelligence but matter less for people high in intelligence. It's harder for people low in intelligence to manage interference, to hold a good strategy in mind while applying it, and to switch the train of thought from one track to another, so they are more likely to perseverate in unproductive categories and to apply easybut-ineffective strategies (e.g., searching memory for previously seen uses for a brick). People high in intelligence, in contrast, can more quickly discard unproductive strategies, switch from unproductive categories to fertile ones, and inhibit obvious and mundane uses that compete for attention. They can thus start strong and do well throughout the task instead of spending the first few minutes wading through and breaking free from mundane ideas.

Method

Participants

The sample was comprised of 133 undergraduate students—92 women, 41 men — from the University of North Carolina at Greensboro. Students volunteered to participate and received credit toward a research option in a psychology class. Based on self-reports, the sample's racial and ethnic composition was diverse-European American (61\%), African American (26\%), Asian American (10\%), and Hispanic/Latino (5\%) —and several people (6\%) selected more than one category. Age ranged from 18 to 48, with a mean of 19.6 ( SD = 3.2). The most common majors were psychology, nursing, undecided, and kinesiology.

Procedure

Participants completed the study in groups of 1 to 8. Upon entering the lab room, participants were given a consent form and a brief explanation of the study. Following informed consent, students completed a divergent thinking task, a series of fluid intelligence tests, and some selfreport questionnaires. The tasks and questionnaires were administered with MediaLab v2010 ( Empirisoft, 2010). The data were collected as part of a larger study on cognitive abilities and creativity. Another paper presents data on a metaphor task that was included ( Silvia \& Beaty, 2012); the creativity data have not been presented elsewhere.

Divergent thinking task

Participants had 10 minutes to generate unusual uses for a brick. Similar to past serial order research ( Christensen et al., 1957; Parnes, 1961; Runco, 1986), we gave people more time than usual to have a larger window to track temporal trends in creative quality. Participants typed each response into text fields presented on a computer screen, and the software time-stamped each response. 
Before starting the task, students were briefed on the characteristics of an appropriate response. We instructed them to "be creative" and "to come up with something clever, humorous, original, compelling, or interesting.” Past research demonstrates that "be creative” instructions increase the quality of responses ( Christensen et al., 1957; Harrington, 1975; Niu \& Liu, 2009). Responses were scored using the subjective scoring method ( Silvia et al., 2008). Three raters scored each response independently on a 1 ( not at all creative) to 5 ( very creative) scale, using criteria of novelty, remoteness, and cleverness. Time-stamped identifiers were removed and the responses were sorted alphabetically prior to scoring, so raters were unaware of an item's serial order, the number of responses a participant provided, which response came from which participant, and all other information about the participants.

Fluid intelligence tasks

After completing the divergent thinking task, students were given a series of six fluid intelligence tests. We chose measures that were spatial and nonverbal to avoid superficial overlap with the verbal divergent thinking task. All tasks were administered electronically using MediaLab. Students completed the following assessments: (1) an abbreviated version of the Ravens Advanced Progressive Matrices (18 items, 12 minutes; see Carroll, 1993); (2) a paper folding task, which asks people to determine the final state of a piece of paper that has been folded, punched with holes, and unfolded (10 items, 3 minutes; Ekstrom, French, Harman, \& Dermen, 1976); (3) a letter sets task, which presents a series of four-letter combinations and requires people to determine which set does not follow a rule governing the other four (16 items, 4 minutes; Ekstrom et al., 1976); (4) the matrices task from the Cattell Culture Fair Intelligence Test (CFIT; Cattell \& Cattell, 1961/2008), in which a pattern must be completed by choosing the missing segment of a matrix (13 items, 3 minutes); (5) the series task from the CFIT, in which a sequence of images must be completed by selecting the next corresponding image (13 items, 3 minutes); and (6) a number series task, in which participants complete a sequence of numbers by discovering a guiding rule (15 items, 4.5 minutes; Thurstone, 1938).

Results

Data Reduction and Descriptive Statistics

Each response was time stamped based on elapsed milliseconds, so we converted each value into decimal time. A value of 1.75 thus means that 1.75 minutes had elapsed (i.e., the 1:45 mark) when the response occurred. To score fluency, we segmented the task into 101 -min blocks and counted the number of responses that occurred in each of the 10 blocks.

Our analyses used multilevel structural equation modeling, an extension of conventional multilevel modeling that includes latent variables ( Heck \& Thomas, 2009). In particular, we modeled creativity as a latent variable with three indicators, one for each rater (see Silvia, 2008c). The divergent thinking ratings were highly skewed-each rater gave at least $75 \%$ of the responses a score of 1 or 2 on the 5-point scale. We always find skewed ratings in our research- 
most responses are mundane, some are pretty good, and a few are great-but this level of skew required treating the ratings as ordinal variables. An ordinal model uses the distribution of scores in each category to estimate each person's underlying trait score, which is assumed to be continuous ( Skrondal \& Rabe-Hesketh, 2004). The factor loadings for the three raters were nearly identical, so we constrained them to be equal to simplify the model. The reliability of the ratings was high: Cronbach's alpha, estimated from the factor loadings ( Hancock \& Mueller, 2001; Silvia, 2011), was .89.

For our analyses, we built up from main effects to full multilevel models. At the between-person level, we estimated the main effect of fluid intelligence; at the within-person level, we estimated the main effect of time. The full models included both main effects as well as their interaction, known as a cross-level interaction. A significant cross-level interaction between fluid intelligence and time would mean that the effect of time on divergent thinking - the serial order effect-varies across levels of intelligence. Between-person predictors were centered at the sample's overall mean; within-person predictors were centered at each person's own mean ( Enders \& Tofighi, 2007). We estimated all models using Mplus 6.1 ( Muthén \& Muthén, 19982010), using maximum likelihood with robust standard errors. Unless noted otherwise, all effects are unstandardized.

\section{Creativity}

We first examined the within-person main effect of time on creativity. For this model, we estimated the linear and quadratic effects of time on creativity, which was specified, as described earlier, as a latent variable indicated by the three raters' scores. Both the linear $(\mathrm{b}=.138, \mathrm{SE}=$ $.016, \mathrm{p}<.001)$ and quadratic effects $(\mathrm{b}=-.018, \mathrm{SE}=.004, \mathrm{p}<.001)$ were significant. Figure 1 depicts the estimated pattern. Our data showed the same trend as past work—responses became increasingly creative across time, but the linear trend flattened toward the end of the time period.

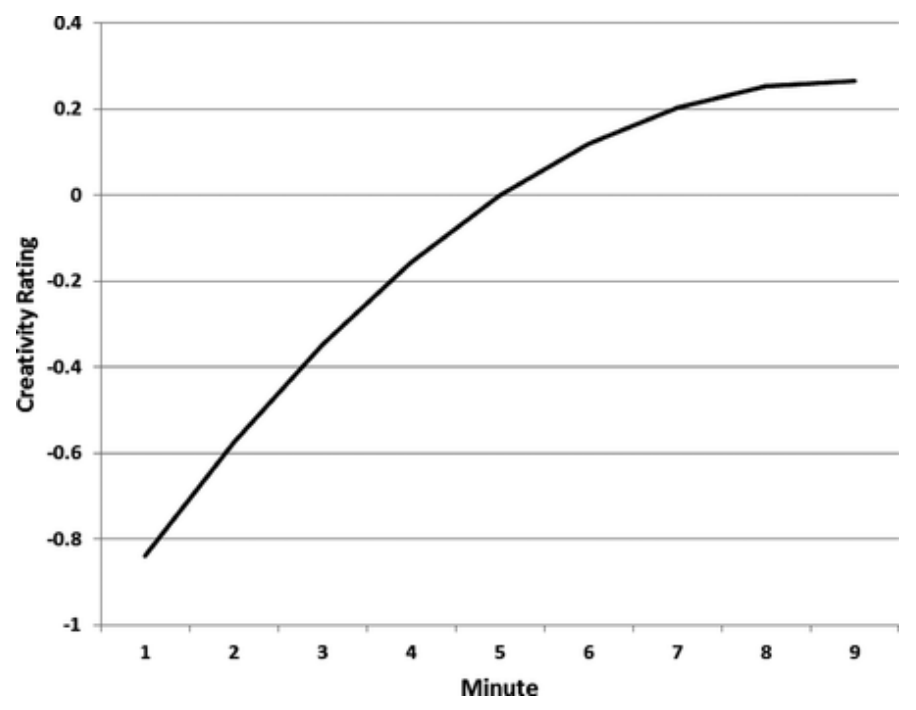


Figure 1 . The creativity of divergent thinking responses across time.

Next, we examined the between-person main effect of fluid intelligence on the creativity of people's divergent thinking responses. Fluid intelligence was specified as a latent variable with six continuous indicators, one for each task. This main effect was significant, $b=.174, S E=$ $.077, p=.024$. An estimate of the standardized effect size was $\beta=.260$.

Finally, we examined whether time and fluid intelligence interacted. To simplify this complex model, we specified fluid intelligence as an observed variable by standardizing and then averaging the six intelligence tasks. The between-person level had fluid intelligence (centered at the sample's grand mean) as a predictor; the within-person level had the linear effect of time (centered at each person's mean) as a predictor. The full model, not surprisingly, found significant main effects of fluid intelligence ( $b=.448, S E=.194, p=.021$ ) and of time ( $b=$ $.112, S E=.012, p<.001)$. More notable was a significant interaction between time and fluid intelligence, $b=-.042, S E=.015, p=.004$.

Figure 2 depicts this interaction as a scatterplot. The $\mathrm{X}$-axis is fluid intelligence; the $\mathrm{Y}$-axis is the size of the time-creativity slope. As intelligence increases, the within-person relationship between time and creativity becomes smaller. In short, the serial order effect diminished as intelligence increased. People high in fluid intelligence had flatter slopes, so the creativity of their responses depended less on time. Stated the other way, people low in fluid intelligence had steeper slopes, so their responses became increasingly creative with time.

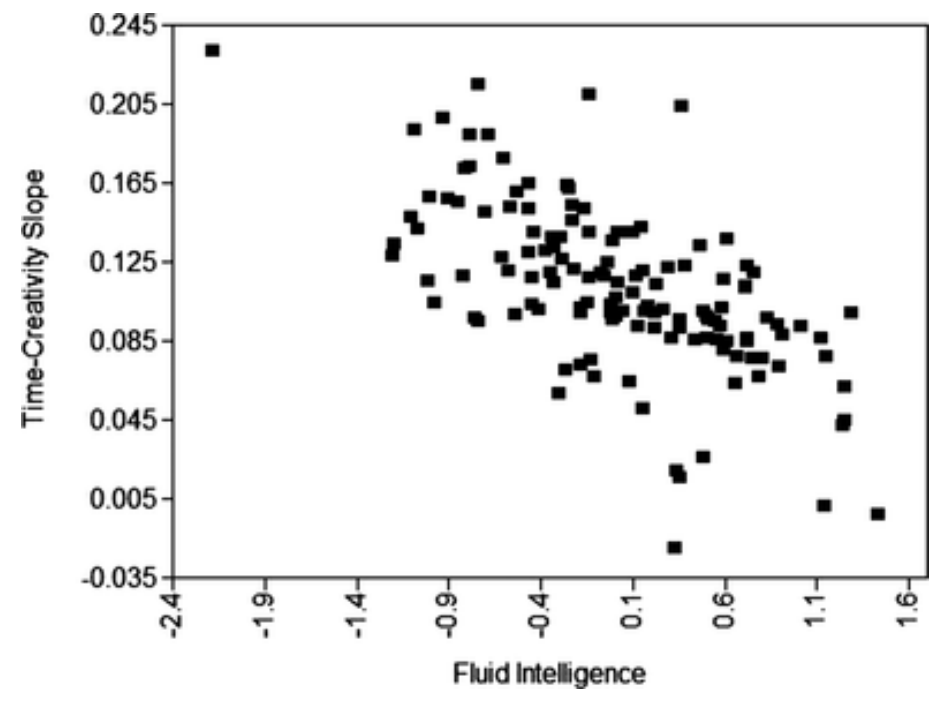

Figure 2. The interaction between fluid intelligence and time.

Fluency

What about fluency across the 10 minutes? On average, people came up with 13.6 responses ( $\mathrm{SD}=6.6$ ), but these responses tended to appear in the task's first few minutes. Figure 3 shows 
the average number of responses generated during each minute of the task. The pattern shows a burst of responses during the first two minutes and a swift decline thereafter.

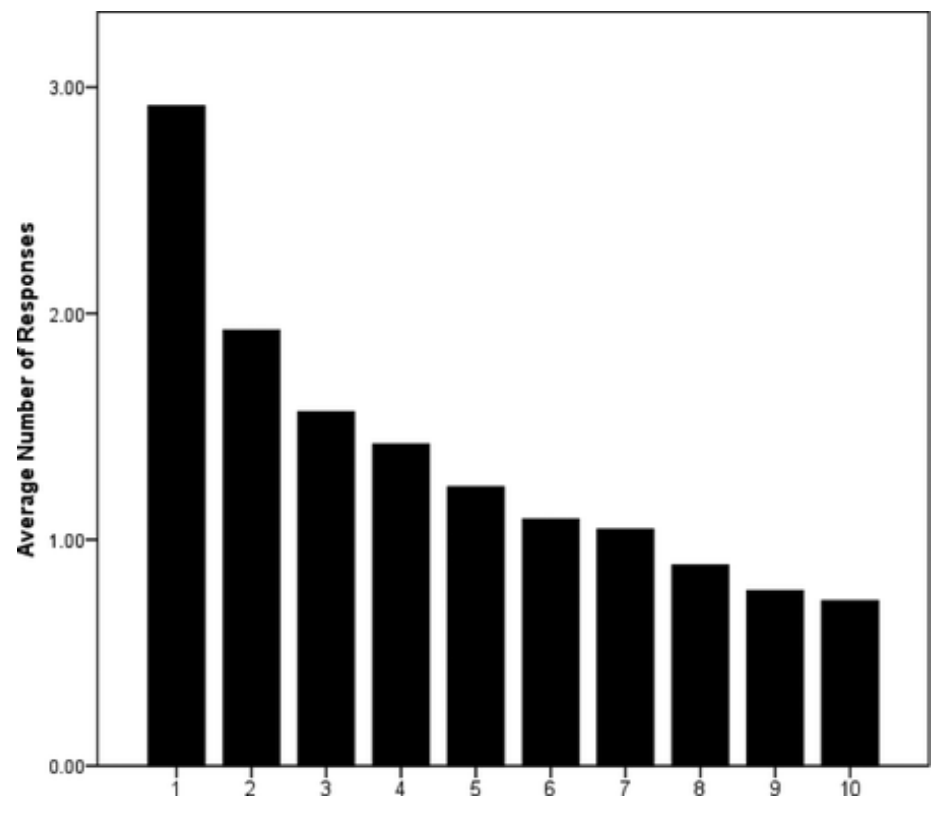

Figure 3. Fluency across the 10 minutes of the task.

As with the creativity scores, we used multilevel models to examine the effects of time and intelligence on fluency. At the within-person level, there were significant linear $(b=-.474, S E=$ $.044, p<.001$ ) and quadratic ( $b=.031, S E=.004, p<.001$ ) effects of time, as one would expect based on the trend shown in Figure 3. At the between-person level, there was no main effect of fluid intelligence, $b=-.509, S E=.773, p=.511$. The estimated standardized effect size was a meager $\beta=-.074$. Furthermore, there was no interaction between time and fluid intelligence ( $b=.016, S E=.017, p=.359$ ). Fluency thus behaved differently than creativity: it started high and swiftly dropped, and fluid intelligence didn't predict overall fluency or fluency's relationship with time. 1

\section{Discussion}

Why are later ideas more creative than earlier ideas? The serial order effect is easy to replicate: many researchers have found it using diverse tasks, samples, and scoring methods. The prevailing explanation, interestingly enough, is the oldest explanation: it takes time for people to reach remote associates on the fringe of a sematic network, so responses become more unique and creative as people move away from close, obvious concepts to remote and uncommon ones. The associative explanation proposed by the early researchers ( Christensen et al., 1957; Mednick, 1962; Parnes, 1961) was compatible with parallel work in verbal fluency ( Bousfield \& Barclay, 1950; Bousfield \& Sedgewick, 1944) and with the period's deep interest in associationism as a component of complex behavior and cognition (e.g., Berlyne, 1965; Hull, 1952). 
It's an irony of history that verbal fluency tasks, an inspiration for the original work on the serial order effect, are now known to involve many executive processes, particularly cue generation, category switching, and interference management ( Troyer et al., 1997; Unsworth et al., 2011). Divergent thinking tasks appear to be receiving a new look, too, given the modern turn toward proposing executive and strategic mechanisms of creative thought (e.g., Benedek et al., 2011; Fink et al., 2009; Gilhooly et al., 2007; Nusbaum \& Silvia, 2011a; Silvia \& Beaty, in press; Zabelina \& Robinson, 2010). Like associative processes, executive processes unfold over time in ways that would create a serial order effect-it takes time for most people to develop a good strategy, overcome interference from obvious ideas, and identify fertile idea categories. As a result, the serial order effect in divergent thinking — like the parallel effect in verbal fluency tasks-might result from the operation of top-down processes, not from simple spreading activation.

To test this idea, we examined the role of fluid intelligence in serial order. Fluid intelligence is central to executive control, so it is a way of capturing individual differences in mental management: the ability to manage interference, to deploy abstract strategies, and to successfully direct attention and thought. Our experiment found a pronounced serial order effect, which replicated prior work. More interesting, however, was the significant moderating effect of fluid intelligence. The serial order effect diminished as intelligence increased, and it was effectively absent at the highest levels of intelligence in our sample (see Figure 2). Taken together, the findings revealed that people higher in fluid intelligence started with better ideas and did better throughout the task - their initial ideas were as good as their later ones.

Because highly intelligent participants didn't show a serial order effect, it seems unlikely that the effect is overall solely due to spreading activation in semantic networks. We should emphasize that our evidence for this claim is indirect and oblique - the experiment didn't directly measure semantic spread, the operation of executive processes within the task, or online verbal reports of people's thoughts and strategies—but we nevertheless think our reasoning is sound in light of the findings. Specifically, the people who performed the best on the divergent thinking task showed no change over time, so it is clear that temporal change isn't essential to doing well. If anything, the long-standing spatial metaphor of moving away from close, obvious ideas toward remote, original ones may be misleading (cf. Moran, 2009). Good ideas needn't be "farther away" in semantic space than bad ideas-indeed, good ideas are often generated by people on the spot, not waiting to be found in the frontiers of memory ( Gilhooly et al., 2007). Instead, people who are more effective at managing their minds can recruit the strategies and processes needed to generate ideas despite interference generated from obvious ideas and entrenched ways of thinking.

Past meta-analyses ( Kim, 2005, 2008) and literature reviews ( Kaufman \& Plucker, 2011; Kim, Cramond, \& VanTassel-Baska, 2010) suggest that creativity and intelligence are modestly related. Our main effect of fluid intelligence on divergent thinking was notably higher $(\beta=.26)$ than the benchmark effect size from Kim's (2005) meta-analysis (around $r=.17$ ). It's worth 
pointing out, however, that our past research has shown that the relationship between intelligence and creativity increases when researchers analyze latent variables ( Silvia, 2008b), assess higherorder factors of intelligence rather than lower-order abilities ( Nusbaum \& Silvia, 2011a, Study 1; Silvia, 2008a), and include several creativity tasks ( Nusbaum \& Silvia, 2011a, Study 2). The present study thus had some strikes against it: it included only one unusually long divergent thinking task, and it analyzed fluid intelligence rather than the higher-order $\mathrm{g}$ factor. As a result, we suspect that this higher-than-average effect size is nevertheless an underestimate of the true effect size, but this is naturally a claim that awaits future work.

As an aside, our findings for fluency nicely round out the experiment. First, fluency started high and then swiftly declined. This replicates prior work, albeit with a more robust method for estimating temporal trajectories. Second, creativity and fluency varied in their predictors. Fluid intelligence had both a main effect and an interactive effect for ratings of creativity, but it had no effects on fluency. Such dissociations have appeared in our past work, and they are one reason why we have advocated for subjective scoring ( Silvia et al., 2008). Traditional methods for scoring divergent thinking, particularly uniqueness scoring and its variants, lead to unusually high correlations between creativity and fluency (e.g., Hocevar, 1979; Silvia, 2008b). Subjective ratings, in contrast, appear to effectively divorce creative quality from mere quantity ( Silvia, Martin, \& Nusbaum, 2009; Silvia et al., 2008).

\section{Executive Mechanisms in Creativity}

Given that our evidence for an executive interpretation of the serial order effect is indirect, it's worth developing some of the likely mechanisms. Our approach to executive aspects of creativity more generally presupposes that there are many entry points for cognitive control in the creative process ( Nusbaum \& Silvia, 2011a), so one would expect a range of processes to be important. One critical mechanism is the ability to inhibit irrelevant information, particularly salient-butobvious responses and prepotent associations. Considering the associative architecture of longterm memory, one can imagine the interference that would arise during a divergent thinking task from the overactivation of high-frequency associates in stored semantic knowledge (i.e., the fan effect; see Anderson, 1983b). To generate unusual uses, it seems likely that some level of associative blocking must occur to inhibit the most closely related elements of a given cue (e.g., a brick). Several models of selective retrieval provide insight into the inhibitory mechanisms involved in overriding prepotent associates that compete for activation in semantic memory (e.g., Anderson, 1983a; Cantor \& Engle, 1993; McGeoch, 1932). Selective retrieval requires the deliberate suppression of salient knowledge ( Bunting, Conway, \& Heitz, 2004; Friedman \& Miyake, 2004; May, Hasher, \& Kane, 1999), an ability that should be useful for generating novel associations during creative cognition.

This contention received support from a study of individual differences in performance on the Remote Associates Task (RAT; Gupta, Jang, Mednick, \& Huber, 2012), perhaps the classic example of a test anchored in the associative tradition. Participants were encouraged to respond 
rapidly to each problem and to guess if necessary. Using computational models, Gupta and colleagues demonstrated that poor performance on the RAT was characterized by a bias toward responding with high-frequency semantic associates of the three RAT cues. Conversely, strong performance was characterized by (1) overcoming high-frequency associates and instead considering low-frequency ones, and (2) correctly evaluating an option as correct or incorrect. These findings are consistent with our view that creative thinking involves managing interference from neighboring associates in semantic memory.

We should note that our findings aren't consistent with an expanded spreading activation model. In such an account, everyone starts with obvious, prepotent ideas that spread toward remote ideas, but only people low in intelligence give the obvious responses. People high in intelligence, in contrast, inhibit the obvious responses and only begin typing their ideas once they have arrived at remote concepts that they feel are creative enough. Such a view thus sees spreading activation as the core process: everyone wades through obvious ideas, and intelligence merely moderates people's ability to inhibit and reject them. Although interesting, this account seems unlikely based on additional analyses. If smart people are simply inhibiting the same prepotent associates that everyone else is typing, then we would expect them to take longer to type their first response, assuming that the rate of semantic spread is similar across intelligence levels and that the process of inhibiting and rejecting ideas requires time. To test this prediction, we correlated Gf (the average of the six z-scored tasks) with how long it took people (in decimal time) to give their first idea in the brick task. The correlation between intelligence and latency was essentially zero ( $\mathrm{r}=-.037, \mathrm{p}=.673$ ), which suggests that people high in fluid intelligence were not simply waiting out the obvious ideas.

But managing knowledge via the control of attention isn't the only executive contribution to the generation of creative ideas. Two other mechanisms - strategy use and goal maintenancedeserve mention. Strategy use received an extensive treatment in Gilhooly et al.'s (2007) protocol analysis of people's verbal reports during unusual uses tasks. As we mentioned earlier, that research found a wide range of strategies that varied in effectiveness. People who came up with better ideas were able to stop the most intuitive strategy (search memory for known uses), identify a better one, and keep it in mind while enacting it. Goal maintenance-the ability to keep a task's goal in mind while performing the task- has not yet been studied in creativity tasks, but it is probably important. People with better cognitive control, such as people with high working memory spans, are less likely to have a task's goal (such as "to be creative" and "generate only creative uses”) slip from mind during the task ( Kane \& Engle, 2003; Marcovitch, Boseovski, Knapp, \& Kane, 2010). Maintaining a goal online during task performance requires stronger executive control of thought, and it seems sensible that smart people generate better ideas in part because they can keep the task's "be creative" goal in mind while simultaneously executing ideational processes.

Integrating Top-Down and Bottom-Up Models of Creative Thought 
Throughout, we have been critical of associative models of creative thought. Our criticism of this tradition has been a bit exaggerated so that we could emphasize the contrast between executive and associative mechanisms. Nevertheless, we do agree that associative processes—even humble spreading activation - are important to creativity, and we suspect that the big problem for future work is to understand the interaction of controlled and automatic aspects of creative thought. Many aspects of thought are hard to control, so intentionally trying to generate creative ideas involves managing a set of processes that, as a group, aren't entirely manageable.

Recent work provides several innovative examples of how executive and associative processes interact. First, some people probably use passive associative cueing as a strategy for idea generation. A humorous example comes from the verbal reports obtained by Gilhooly et al. (2007). Several of their participants simply repeated the name of the object to themselves (e.g., "brick... brick... brick") in an attempt to spark ideas. This strategy won't often yield original ideas — it will yield ideas already stored in memory, not novel ones—but it does show how people can deliberately try to spark ideas using associative spread.

Second, people vary in associative abilities. In one of the few studies of associative abilities and creativity, Benedek, Könen, and Neubauer (in press) developed a series of tasks that required generating words according to associative constraints. As a set, the associative abilities explained over half the variance in divergent thinking fluency, but two kinds of abilities emerged as particularly important. The first, associative combination, is the ability to generate a word that was associated with each word in a pair of words. The second, dissociative ability, is the ability to generate semantically unrelated words. These two abilities involve many features of higherorder thought, such as discerning abstract relationships and inhibiting semantic knowledge, and the findings illustrate how seemingly low-level processes can recruit general mechanisms of cognitive control.

Third, low-level associative processes can be viewed in terms of dynamic systems that exhibit features of executive processes - selection, inhibition, and goal-direction-but do so based on self-organizing dynamic qualities, not intentional top-down input. The best-known example is Gabora's $(2005,2010)$ honing theory, which examines self-organizing properties of low-level conceptual and memory systems. The conventional way of viewing semantic knowledge in creativity has been to focus on spreading activation (e.g., the traditional explanation for the serial-order effect) or on the structure of semantic knowledge (e.g., research on how prior knowledge states affect creativity and problem-solving; Weisberg, 2006). In honing theory, in contrast, knowledge systems themselves can self-organize and interact according to dynamic rules. The end result can appear directed, but the processes unfold based on the low-level system's initial state, rules, contents, and organizational tendencies. Unlike the other approaches, then, honing theory views associative processes as goal-directed, but the person needn't exercise agency or intention for them to unfold. If developed to examine how intelligence and creativity relate, honing theory might offer the most problematic critique of an executive approach: creativity's top-down appearance would be only specious. 


\section{Some Limitations and Directions for Future Work}

The present research offered a new interpretation of the serial order effect and illustrated how new methods and statistical models can be used to test it, but there are several limitations that would serve as fruitful directions for future work. First, the experiment used fluid intelligence as a proxy for a family of executive abilities, but it would be worthwhile to untangle them. For example, measuring strategy use via think-alouds or prompts embedded in the task, assessing interference management directly ( Unsworth, 2010), or manipulating variables that would affect interference, switching, and executive capacity would shed light on the mechanisms behind our global effect. Second, fluid intelligence is one of several cognitive abilities within modern models of the structure of intelligence (e.g., Carroll, 1993). Several other abilities—such as crystallized intelligence (Gc) and retrieval ability (Gr) — are relevant to creativity broadly and to the intersection of executive and associative processes specifically. A more expansive assessment of cognitive abilities that incorporated innovations in assessing Gc and Gr (e.g., Benedek, Könen, \& Neubauer, in press; Rolfhus \& Ackerman, 1999) would be an important next step. Finally, the present work showed how new methods can be applied to studying the serial order effect that avoid the vexing statistical problems found in past work. The serial order effect is a good paradigm for studying how creative thought unfolds over time, so studying moderators beyond the few considered here would be productive.

\section{Conclusion}

The serial order effect is one of the oldest empirical findings in creativity research, and it is central to models of divergent thinking that presume a spread of activation toward increasingly remote associations (e.g., Wallach \& Kogan, 1965). Nevertheless, modern research on executive aspects of creative thought suggests that some executive control over creativity is possible, so perhaps some people can arrive at good ideas without first wading through bad ones. In our research, the serial order effect diminished as fluid intelligence increased. Because smart people did better overall and generated consistently good responses throughout the task, two things are clear: (1) people needn't first work through poor ideas to arrive at good ones, and (2) creative ideas can be recruited and developed in the absence of associative spread. This work further supports the emerging interest in executive aspects of creative thought and suggests that the underpinnings of the classic serial order effect deserve a new look.

\section{Footnotes}

1 Although fluid intelligence is the central focus of this research, it's worth noting some effects of personality, given the large literature on personality and creativity. A first set of analyses explored between-person main effects of the Big Five Factors, measured with the 60-item NEO Five Factor Inventory (NEO-FFI; Costa \& McCrae, 1992). Only one of them-openness to experience, naturally_predicted creativity. Consistent with a vast amount of work (see Feist, 1998; Silvia, Nusbaum, Berg, Martin, \& O'Connor, 2009; Nusbaum \& Silvia, 2011b), people 
high in openness generated ideas that were more creative, $b=1.561, S E=.256, p<.001$. None of the other four factors had a significant effect. Furthermore, there were no significant crosslevel interactions involving the five factors, so the effects of time on creativity were independent of personality. Similar effects appeared for fluency: openness to experience ( $b=.261$, $S E=$ $.110, p=.017$ ) and neuroticism ( $b=.157, S E=.079, p=.048$ ) had main effects on fluency, but none of the cross-level interactions was significant.

\section{References}

Anderson, J. R. ( 1983a). A spreading activation theory of memory. Journal of Verbal Learning and Verbal Behavior, 22, 261- 295. doi: 10.1016/S0022-5371(83)90201-3

Anderson, J. R. ( 1983b). Retrieval of information from long-term memory. Science, 220, 2530. doi: 10.1126/science.6828877

Benedek, M., Bergner, S., Könen, T., Fink, A., \& Neubauer, A. C. ( 2011). EEG alpha synchronization is related to top-down processing in convergent and divergent thinking.Neuropsychologia., 49, 3505- 3511.

Benedek, M., Könen, T., \& Neubauer, A. ( in press). Associative abilities underlying creativity. Psychology of Aesthetics, Creativity, and the Arts.

Berlyne, D. E. ( 1965). Structure and direction in thinking. New York: Wiley.

Bousfield, W. A., \& Barclay, W. D. ( 1950). The relationship between order and frequency of occurrence of restricted associated responses. Journal of Experimental Psychology, 40, 643647. doi: 10.1037/h0059019

Bousfield, W. A., \& Sedgewick, C. H. ( 1944). An analysis of sequences of restricted associative responses. Journal of General Psychology, 30, 149- 165.

Bunting, M. F., Conway, A. A., \& Heitz, R. P. ( 2004). Individual differences in the fan effect and working memory capacity. Journal of Memory and Language, 51, 604- 622. doi: 10.1016/j.jml.2004.07.007

Burgess, G. C., Gray, J. R., Conway, A. A., \& Braver, T. S. ( 2011). Neural mechanisms of interference control underlie the relationship between fluid intelligence and working memory span. Journal of Experimental Psychology: General, 140, 674- 692. doi: 10.1037/a0024695

Cantor, J., \& Engle, R. W. ( 1993). Working-memory capacity as long-term memory activation: An individual-differences approach. Journal of Experimental Psychology: Learning, Memory, and Cognition, 19, 1101- 1114. doi: 10.1037/0278-7393.19.5.1101

Carroll, J. B. ( 1993). Human cognitive abilities: A survey of factor-analytic studies. New York: Cambridge University Press. doi: 10.1017/CBO9780511571312 
Cattell, R. B., \& Cattell, A. K. S. ( 1961/2008). Measuring intelligence with the Culture Fair Tests. Oxford, UK: Hogrefe.

Christensen, P. R., Guilford, J. P., \& Wilson, R. C. ( 1957). Relations of creative responses to working time and instructions. Journal of Experimental Psychology, 53, 82- 88. doi:

\subsection{7/h0045461}

Cohen, J. ( 1983). The cost of dichotomization. Applied Psychological Measurement, 7, 249253. doi: 10.1177/014662168300700301

Conway, A. R. A., Kane, M. J., \& Engle, R. W. ( 2003). Working memory capacity and its relation to general intelligence. Trends in Cognitive Sciences, 7, 547- 552. doi:

10.1016/j.tics.2003.10.005

Costa, P. T., Jr., \& McCrae, R. R. ( 1992). Revised NEO Personality Inventory (NEO-PI-R) and NEO Five-Factor Inventory (NEO-FFI) professional manual. Odessa, FL: Psychological Assessment Resources.

De Dreu, C. K. W., Nijstad, B. A., Bass, M., Wolsink, I., \& Roskes, M. ( 2012). Working memory benefits creative insight, musical improvisation, and original ideation through maintained task-focused attention. Personality and Social Psychology Bulletin, 38, 656- 669.

Ekstrom, R. B., French, J. W., Harman, H. H., \& Dermen, D. ( 1976). Manual for Kit of FactorReferenced Cognitive Tests. Princeton, NJ: Educational Testing Service.

Empirisoft. ( 2010). MediaLab(Version 2010) [Computer software]. New York: Author.

Enders, C. K., \& Tofighi, D. ( 2007). Centering predictor variables in cross-sectional multilevel models: A new look at an old issue. Psychological Methods, 12, 121-138. doi: 10.1037/1082989X.12.2.121

Enders, C. K. ( 2010). Applied missing data analysis. New York: Guilford.

Ericsson, K. A., \& Simon, H. A. ( 1980). Verbal reports as data. Psychological Review, 87, 215251. doi: 10.1037/0033-295X.87.3.215

Feist, G. J. ( 1998). A meta-analysis of personality in scientific and artistic creativity. Personality and Social Psychology Review, 2, 290- 309. doi: 10.1207/s15327957pspr0204_5

Fink, A., Grabner, R. H., Benedek, M., Reishofer, G., Hauswirth, V., Fally, M., .. . Neubauer, A. C. ( 2009). The creative brain: Investigation of brain activity during creative problem solving by means of EEG and fMRI. Human Brain Mapping, 30, 734- 748. doi: 10.1002/hbm.20538

Finke, R. A., Ward, T. B., \& Smith, S. M. ( 1992). Creative cognition: Theory, research, and applications. Cambridge, MA: MIT Press. 
Friedman, N. P., \& Miyake, A. ( 2004). The relations among inhibition and interference control processes: A latent variable analysis. Journal of Experimental Psychology: General, 133, 101135. doi: 10.1037/0096-3445.133.1.101

Gabora, L. ( 2005). Creative thought as a non-Darwinian evolutionary process. Journal of Creative Behavior, 39, 262- 283. doi: 10.1002/j.2162-6057.2005.tb01261.x

Gabora, L. ( 2010). Revenge of the "neurds": Characterizing creative thought in terms of the structure and dynamics of memory. Creativity Research Journal, 22, 1- 13. doi:

10.1080/10400410903579494

Gilhooly, K. J., Fioratou, E., Anthony, S. H., \& Wynn, V. ( 2007). Divergent thinking: Strategies and executive involvement in generating novel uses for familiar objects. British Journal of Psychology, 98, 611-625. doi: 10.1111/j.2044-8295.2007.tb00467.x

Gupta, N., Jang, Y., Mednick, S. C., \& Huber, D. E. ( 2012). The road not taken: Creative solutions require avoidance of high-frequency responses. Psychological Science, 23, 288- 294.

Hancock, G. R., \& Mueller, R. O. ( 2001). Rethinking construct reliability within latent variable systems. In R.Cudeck, S.du Toit, \& D.Sörbom ( Eds.), Structural equation modeling: Present and future (pp. 195- 216). Lincolnwood, IL: Scientific Software International.

Harrington, D. M. ( 1975). Effects of explicit instructions to "be creative" on the psychological meaning of divergent thinking test scores. Journal of Personality, 43, 434- 454. doi: 10.1111/j.1467-6494.1975.tb00715.x

Heck, R. H., \& Thomas, S. L. ( 2009). An introduction to multilevel modeling techniques ( 2nd ed.). New York: Routledge.

Hocevar, D. ( 1979). Ideational fluency as a confounding factor in the measurement of originality. Journal of Educational Psychology, 71, 191- 196. doi: 10.1037/0022-0663.71.2.191 Hull, C. L. ( 1952). A behavior system. New Haven, CT: Yale University Press.

Johns, G. A., Morse, L. W., \& Morse, D. T. ( 2001). An analysis of early vs. later responses on a divergent production task across three time press conditions. Journal of Creative Behavior, 35, 65- 72. doi: 10.1002/j.2162-6057.2001.tb01222.x

Kane, M. J., \& Engle, R. W. ( 2003). Working-memory capacity and the control of attention: The contributions of goal neglect, response competition, and task set to Stroop interference. Journal of Experimental Psychology: General, 132, 47- 70. doi: 10.1037/0096-3445.132.1.47

Kaufman, J. C., \& Plucker, J. A. ( 2011). Intelligence and creativity. In R. J.Sternberg \& S.Kaufman ( Eds.), The Cambridge handbook of intelligence (pp. 771- 783). New York, NY: Cambridge University Press. 
Kaufman, J. C. ( 2009). Creativity 101. New York: Springer.

Kim, K. H., Cramond, B., \& VanTassel-Baska, J. ( 2010). The relationship between creativity and intelligence. In J. C.Kaufman \& R. J.Sternberg ( Eds.), The Cambridge handbook of creativity (pp. 395- 412). New York, NY: Cambridge University Press. doi: 10.1017/CBO9780511763205.025

Kim, K. H. ( 2005). Can only intelligent people be creative? Journal of Secondary Gifted Education, 16, 57-66.

Kim, K. H. ( 2008). Meta-analyses of the relationship of creative achievement to both IQ and divergent thinking test scores. Journal of Creative Behavior, 42, 106- 130. doi: 10.1002/j.21626057.2008.tb01290.x

Luke, D. A. ( 2004). Multilevel modeling. (Sage University Paper Series on Quantitative Applications in the Social Sciences, series no. 07-143). Newbury Park, CA: Sage.

Marcovitch, S., Boseovski, J. J., Knapp, R. J., \& Kane, M. J. ( 2010). Goal neglect and working memory capacity in 4- to 6-year-old children. Child Development, 81, 1687-1695. doi: 10.1111/j.1467-8624.2010.01503.x

Maxwell, S. E., \& Delaney, H. D. ( 1993). Bivariate median splits and spurious statistical significance. Psychological Bulletin, 113, 181- 190. doi: 10.1037/0033-2909.113.1.181

May, C. P., Hasher, L., \& Kane, M. J. ( 1999). The role of interference in memory span. Memory \& Cognition, 27, 759- 767. doi: 10.3758/BF03198529

McGeoch, J. A. ( 1932). Forgetting and the law of disuse. Psychological Review, 39, 352- 370. doi: 10.1037/h0069819

McGrew, K. S. ( 2005). The Cattell-Horn-Carroll theory of cognitive abilities. In D. P.Flanagan \& P. L.Harrison ( Eds.) , Contemporary intellectual assessment: Theories, tests, and issues ( 2nd ed., pp. 136-181). New York, NY: Guilford.

Mednick, S. A. ( 1962). The associative basis of the creative process. Psychological Review, 69, 220- 232. doi: $10.1037 / \mathrm{h} 0048850$

Milgram, R. M., \& Rabkin, L. ( 1980). Developmental test of Mednick's associative hierarchies of original thinking. Developmental Psychology, 16, 157- 158. doi: 10.1037/0012-1649.16.2.157

Moran, S. ( 2009). Metaphor foundations in creativity research: Boundary vs. organism. Journal of Creative Behavior, 43, 1- 22. doi: 10.1002/j.2162-6057.2009.tb01303.x

Muthén, L. K., \& Muthén, B. O. ( 1998-2010). Mplus user's guide ( 6th ed.). Los Angeles, CA: Muthén and Muthén. 
Niu, W., \& Liu, D. ( 2009). Enhancing creativity: A comparison between effects of an indicative instruction "to be creative" and a more elaborate heuristic instruction on Chinese student creativity. Psychology of Aesthetics, Creativity, and the Arts, 3, 93-98. doi: 10.1037/a0013660

Nusbaum, E. C., \& Silvia, P. J. ( 2011a). Are intelligence and creativity really so different? Fluid intelligence, executive processes, and strategy use in divergent thinking. Intelligence,39, 36- 45. doi: 10.1016/j.intell.2010.11.002

Nusbaum, E. C., \& Silvia, P. J. ( 2011b). Are openness and intellect distinct aspects of openness to experience? A test of the O/I model. Personality and Individual Differences, 51, 571- 574. doi: 10.1016/j.paid.2011.05.013

Parnes, S. J. ( 1961). Effects of extended effort in creative problem solving. Journal of Educational Psychology, 52, 117- 122. doi: 10.1037/h0044650

Phillips, V. K., \& Torrance, E. P. ( 1977). Levels of originality at earlier and later stages of creativity test tasks. Journal of Creative Behavior, 11, 147. doi: 10.1002/j.21626057.1977.tb00602.x

Raudenbush, S. W., \& Bryk, A. S. ( 2002). Hierarchical linear models: Applications and data analysis methods ( 2nd ed.). Thousand Oaks, CA: Sage.

Rolfhus, E. L., \& Ackerman, P. L. ( 1999). Assessing individual differences in knowledge: Knowledge structures and traits. Journal of Educational Psychology, 91, 511- 526. doi: 10.1037/0022-0663.91.3.511

Runco, M. A. ( 1986). Flexibility and originality in children's divergent thinking. Journal of Psychology: Interdisciplinary and Applied, 120, 345- 352. doi:

10.1080/00223980.1986.9712632

Runco, M. A. ( 2007). Creativity. San Diego, CA: Academic Press.

Sawyer, R. K. ( 2011). The cognitive neuroscience of creativity: A critical review. Creativity Research Journal, 23, 137- 154. doi: 10.1080/10400419.2011.571191

Silvia, P. J., \& Beaty, R. E. ( 2012). Making creative metaphors: The importance of fluid intelligence for creative thought. Intelligence, 40, 343- 351.

Silvia, P. J., Martin, C., \& Nusbaum, E. C. ( 2009). A snapshot of creativity: Evaluating a quick and simple method for assessing divergent thinking. Thinking Skills and Creativity, 4, 79- 85. doi: 10.1016/j.tsc.2009.06.005

Silvia, P. J., Nusbaum, E. C., Berg, C., Martin, C., \& O'Connor, A. ( 2009). Openness to experience, plasticity, and creativity: Exploring lower-order, higher-order, and interactive effects. Journal of Research in Personality, 43, 1087- 1090. doi: 10.1016/j.jrp.2009.04.015 
Silvia, P. J., Winterstein, B. P., Willse, J. T., Barona, C. M., Cram, J. T., Hess, K. I., Martinez, J. L., \& Richard, C. A. ( 2008). Assessing creativity with divergent thinking tasks: Exploring the reliability and validity of new subjective scoring methods. Psychology of Aesthetics, Creativity, and the Arts, 2, 68- 85. doi: 10.1037/1931-3896.2.2.68

Silvia, P. J. ( 2008a). Another look at creativity and intelligence: Exploring higher-order models and probable confounds. Personality and Individual Differences, 44, 1012- 1021. doi: 10.1016/j.paid.2007.10.027

Silvia, P. J. ( 2008b). Creativity and intelligence revisited: A latent variable analysis of Wallach and Kogan (1965). Creativity Research Journal, 20, 34- 39. doi: 10.1080/10400410701841807

Silvia, P. J. ( 2008c). Discernment and creativity: How well can people identify their most creative ideas?Psychology of Aesthetics, Creativity, and the Arts, 2, 139-146. doi:

10.1037/1931-3896.2.3.139

Silvia, P. J. ( 2011). Subjective scoring of divergent thinking: Examining the reliability of unusual uses, instances, and consequences tasks. Thinking Skills and Creativity, 6, 24- 30. doi: 10.1016/j.tsc.2010.06.001

Singer, J. D., \& Willett, J. B. ( 2003). Applied longitudinal data analysis: Modeling change and event occurrence. New York: Oxford University Press.

Skrondal, A., \& Rabe-Hesketh, S. ( 2004). Generalized latent variable modeling: Multilevel, longitudinal, and structural equation models. Boca Raton, FL: Chapman \& Hall/CRC.

Süß, H. M., Oberauer, K., Wittman, W. W., Wilhelm, O., \& Schulze, R. ( 2002). Workingmemory capacity explains reasoning ability_And a little bit more. Intelligence, 30, 261- 288. doi: 10.1016/S0160-2896(01)00100-3

Thurstone, L. L. ( 1938). Primary mental abilities. Chicago, IL: University of Chicago Press.

Troyer, A. K., Moscovitch, M., \& Winocur, G. ( 1997). Clustering and switching as two components of verbal fluency: Evidence from younger and older healthy adults.Neuropsychology, 11, 138- 146. doi: 10.1037/0894-4105.11.1.138

Unsworth, N., Spillers, G. J., \& Brewer, G. A. ( 2011). Variation in verbal fluency: A latent variable analysis of clustering, switching, and overall performance. Quarterly Journal of Experimental Psychology, 64, 447- 466. doi: 10.1080/17470218.2010.505292

Unsworth, N. ( 2010). Interference control, working memory capacity, and cognitive abilities: A latent variable analysis. Intelligence, 38, 255- 267. doi: 10.1016/j.intell.2009.12.003

Vartanian, O. ( 2009). Variable attention facilitates creative problem solving. Psychology of Aesthetics, Creativity, and the Arts, 3, 57- 59. doi: 10.1037/a0014781 
Vartanian, O. ( 2011). Decision junctures in the creative process. In O.Vartanian \& D. R.Mandel ( Eds.), Neuroscience of decision making (pp. 311- 327). New York, NY: Psychology Press.

Wallach, M. A., \& Kogan, N. ( 1965). Modes of thinking in young children: A study of the creativity-intelligence distinction. New York: Holt, Rinehart, \& Winston.

Ward, W. C. ( 1969). Rate and uniqueness in children's creative responding. Child Development, 40, 869- 878. doi: 10.2307/1127195

Weisberg, R. W. ( 2006). Creativity: Understanding innovation in problem solving, science, invention, and the arts. Hoboken, NJ: Wiley.

Zabelina, D. L., Robinson, M. D., Council, J. R., \& Bresin, K. ( 2012). Patterning and nonpatterning in creative cognition: Insights from performance in a random number generation task. Psychology of Aesthetics, Creativity, and the Arts, 6, 137- 145.

Zabelina, D. L., \& Robinson, M. D. ( 2010). Creativity as flexible cognitive control. Psychology of Aesthetics, Creativity, and the Arts, 4, 136- 143. doi: 10.1037/a0017379

Submitted: November 29, 2011 Revised: April 3, 2012 Accepted: May 8, 2012 